\title{
A SINGULARIDADE DO SINTOMA: POR UMA CRÍTICA PSICANALÍTICA À IDÉIA DE ORIGEM
}

\author{
Fernanda Canavêz*
}

Regina Herzog**

\section{RESUMO}

O objetivo deste artigo é mostrar como a problematização da noção de origem promove inflexōes na concepção de sintoma para Freud, o que acarretou inclusive transformações na técnica psicanalítica. Dessa forma, o sintoma passa a ocupar um lugar fundamental na dinâmica psíquica, revelando toda a sua originalidade que fala a favor do sujeito e que, por isso, deve ser positivada pelo psicanalista.

Palavras-chave: origem, modernidade, sintoma, cura, singularidade

\section{AbSTRACT}

SYMPTOM'S SINGULARITY: FOR A PSYCHOANALYTIC CRITICISM OF THE IDEA OF ORIGIN

The purpose of this article is to show how the notion of origin promotes inflection in the conception of symptoms by Freud, which has, actually, brought changes in psychoanalytic technique. In this way, the symptom begins to hold a fundamental place in the psychic dynamic, revealing all of its originality, which speaks in favor of the subject and, for this reason, should be positively valued by the psychoanalyst.

Keywords: origin, modernity, symptom, cure, singularity

* Mestranda do Programa de Pós-Graduação em Teoria Psicanalítica (Universidade Federal do Rio de Janeiro); Bolsista do CNPq.

** Professora Adjunta do Programa de Pós-Graduação em Teoria Psicanalítica (Universidade Federal do Rio de Janeiro); Bolsista de Produtividade em Pesquisa do CNPq. 


\section{INTRODUÇÃO}

"Por que eu sofro assim?" ou “O que me faz ser assim?” são perguntas comumente endereçadas pelos pacientes àqueles que se ocupam do ofício de analisar. Interessante é notar que, ainda que se sustente o silêncio como resposta ou a impossibilidade de solucionar as questões em definitivo, estas não cessam de retornar. Frente à demanda de resolução de enigmas, cabe a nós, analistas, a tarefa de não tamponá-los, recolocando-os, quando necessário.

A tentativa de se chegar à origem do sofrimento ou à nossa própria "essência”, conforme alguns pacientes almejam, como a explicação derradeira de onde tudo teria surgido, parece presente em diferentes épocas na história da humanidade. Todavia, esta busca ganhou matizes distintos ao longo dos tempos e foi somente na Modernidade - período que abrange o final do século XIX, início do XX - que começou a sofrer algum abalo significativo, ainda que também aí estivesse presente, revelando um paradoxo. O paradoxo que caracteriza a Modernidade diz respeito à coexistência da exaltação de um ideal progressista e uma crítica rigorosa a este ideal (Farah, Herzog \& Mograbi, 2006). Foi neste solo que a psicanálise floresceu. Acompanhando este paradoxo, ao mesmo tempo que reconhecidamente herdeiro deste modo de pensar, Freud se mostrou um crítico contumaz quanto à busca das origens.

O presente artigo pretende se debruçar sobre esta dupla corrente que impregnou a psicanálise. Para tanto, propomos tomar a questão do sintoma na obra freudiana como fio condutor. Assim, veremos como, embora seja possível depreender dos textos mais iniciais de Freud impasses frente ao projeto de se chegar a uma suposta origem do sintoma, o pai da psicanálise mostra-se diversas vezes como um cientista que espera descobrir uma causa precipitadora, um núcleo último das neuroses passível de ser desvelado, levando-se um processo analítico a cabo.

Deste modo, objetivamos mostrar, através da trama conceitual freudiana, como a crítica à idéia de origem é contextualizada historicamente. Vale pontuar que a tentativa de se chegar a uma origem será identificada neste artigo à "busca da essência, da perfeição e da verdade" (Chaves, 1988: 66). Além disso, este percurso que implica uma mudança de perspectiva também nos abre outras possibilidades para refletir sobre o sintoma. Isto porque a escolha freudiana de retirar o foco da pesquisa de sua suposta origem não se dá sem maiores conseqüências - teóricas e, especialmente, clínicas. Pretendemos discutir como o sentido do sintoma ganha outras colorações a partir do abandono da temática da origem, revelando-se de fundamental importância para a dinâmica psíquica, inclusive para aquele que dele se queixa. 


\section{O FÉRTIL SOLO FREUDIANO}

A concepção de sintoma de Freud divergia da até então vigente, ditada pelo discurso científico, essencialmente positivista. Para a ciência moderna importava uma explicação racional e visível para a patologia, valorizando a pesquisa da causa das enfermidades. Os pacientes histéricos, no entanto, apresentavam membros paralisados, tinham alucinações dos mais variados tipos, contraturas, ataques convulsivos, analgesias e outras tantas manifestações aparentemente sem razão; toda uma sintomatologia que não contava com qualquer substrato anatomopatológico capaz de explicar sua aparição no corpo, mas que deveria ser eliminada para que as histéricas ficassem curadas. A cura que era almejada coincidia com a total remissão sintomática, que deveria ser obtida o mais rápido possível. Em contrapartida, Freud supunha que o sintoma denotava um conflito intransponível, colocando em jogo forças opostas que não poderiam ser anuladas.

Ao começar sua investigação sobre a histeria, Freud se deparou com sintomas que ficavam à margem do discurso científico por não se enquadrarem no modelo explicativo pré-estabelecido, tido como uma das máximas da ciência moderna. Esta máxima impunha a necessidade de uma relação lógica entre o sintoma e sua causa precipitadora que fosse visível, presente em alguma disfunção fisiológica. É com este cenário que Freud se defronta e passa a perseguir com afinco, como um cientista moderno, as pistas indicativas da suposta causalidade inerente às enfermidades histéricas. Entretanto, não encontrando esta visibilidade, Freud oferece sua escuta, passando a conferir estatuto de verdade às falas das pacientes. Isso porque, mesmo escapando ao modelo de enfermidades estabelecido até então, os sintomas não deixavam de acossar as mulheres que deles se queixavam ao jovem psicanalista. Este reconheceu a força que animava os relatos histéricos, responsável pela produção sintomática que se revelava como uma positividade. Tratava-se de "uma modalidade de palavra, uma maneira discursiva de existência, que se dizia pela ação, já que não podia ser literalmente enunciada que não lhe retirava, evidentemente, a presença e mesmo o poder de enunciação" (Birman, 2000: 256).

Já dos escritos iniciais de Freud podemos extrair esta perspectiva, a saber, o privilégio dado à escuta das queixas das pacientes, conferindo um valor a estas. $\mathrm{O}$ autor sustentava que a partir de tal escuta a etiologia dos sintomas poderia ser descoberta. Vale ressaltar, no entanto, que esta busca das causas dos sintomas diferia substancialmente daquela empreendida pelos demais cientistas de sua época. Segundo o discurso médico dominante, cabia demonstrar que os fatores etiológicos tinham na hereditariedade sua sustentação teórica. $\mathrm{O}$ posicionamento 
freudiano frente ao tema aparece no "Rascunho K" ([1895] 1974). Contra o pensamento científico em voga, ele declara não acreditar que a hereditariedade seja determinante para a escolha de um tipo de neurose ${ }^{1}$. E mais, para ele, o sintoma relacionava-se à defesa contra o desprazer, sentido por ocasião de uma idéia de conteúdo sexual, traumática. Além disso, a própria escolha da neurose estava associada à idade em que o trauma ocorrera, posição que foi abandonada quatro anos depois na "Carta 125" ([1899] 1974). Nesta carta, Freud esboça a teoria da sexualidade, teoria que vai orientar suas próximas pesquisas. De acordo com esta, a escolha da neurose se dá a partir de fixações em certo período do desenvolvimento sexual, noção que culminará com a publicação de "Três ensaios sobre a teoria da sexualidade" ([1905] 1974). Com esta configuração teórica Freud descarta a hipótese de que a motivação para a formação dos sintomas era decorrente de fatores hereditários.

Este panorama apresenta uma filiação teórica precisa: em uma época marcada pelo cientificismo positivista, tendo a física como modelo a ser seguido, Freud participou de uma verdadeira reviravolta que teve lugar no pensamento epistemológico; trata-se, no final do século XIX, do surgimento das Geisteswissenschaften. Estas correspondiam às ciências do espírito, cuja palavra de ordem era a compreensão. Em contrapartida, as Naturwissenschaften diziam respeito às ciências naturais, que buscavam explicar através de leis os fenômenos da natureza. Freud tomou estas últimas como referência em seus estudos, mas "superou a dualidade, provocando uma descontinuidade com os saberes de sua época. Pois o método que inaugurou conjugou tanto as leis formadoras dos processos psíquicos, quanto o sentido que delas se produzirá” (Bernardes, 2000: 15-16). Para além da filiação freudiana à epistemologia do seu tempo, esta escolha se deve, segundo nosso modo de ver, ao fato de Freud postular a existência do inconsciente, contrapondo-se à tradição filosófica vigente (Herzog, 1999). Assim, é no próprio terreno dos "cientistas da natureza" que Freud propõe fundamentar sua teoria.

Tendo o inconsciente como objeto de estudo e lançando mão de seu percurso como cientista, Freud dedicar-se-á à investigação da etiologia das neuroses. $\mathrm{Na}$ primeira metade do século XIX, observa-se um esforço para distinguir as ciências naturais das ciências do espírito. O autor coloca-se, portanto, em lugar de descontinuidade no que tange aos saberes vigentes, rompendo com a separação entre as explicações calcadas em relações de causa-efeito e aquelas que objetivavam estabelecer relações de sentido através da compreensão. A psicanálise se constituiu no momento em que o campo epistêmico estava em plena revolução e seu criador parece não ter se filiado totalmente a nenhum dos dois tipos de ciência, encontrando, entretanto, um outro lugar para a sua disciplina (Assoun, 1981). 
É irrefutável a exigência de pesquisa da causa dos sintomas histéricos neste momento: tratava-se de dar os subsídios à proposta de um tratamento eficaz para as afecções. Esta tentativa traduz o espírito determinista da época: uma causa produz efeitos e, fazendo-se cessar o que os provoca, estes poderiam ser extintos. Freud também busca um tratamento eficaz; ainda que rejeite uma etiologia precisa para o sintoma, dá ênfase à noção de determinismo psíquico, a qual pressupõe tantos elementos determinantes - daí a consideração do sintoma como sobredeterminado ([1893-95] 1974) - que acaba desembocando numa indeterminação radical, se seguirmos à risca o paradigma científico da época. Para Freud, muitos elementos concorrem para a formação do sintoma, sendo que não há um único conteúdo que responda por sua constituição; tanto este como as demais formações do inconsciente expressam uma superposição de sentidos. Notamos, então, que por mais que tenha se valido do significante determinismo, expressando toda sua herança científica, Freud não abre mão de se distinguir de tal tradição, fazendo recair a ênfase no psiquismo. A pá de cal sobre um último resquício determinista é lançada com a postulação da pulsão de morte, como apontaremos adiante.

Desse modo, sugerimos uma passagem, na obra freudiana, de uma concepção marcadamente determinista (Freud, [1893-95] 1974), na qual a exigência de se buscar uma origem para o sintoma era evidente, para uma orientação mais historicizada, característica da Modernidade, em que claudica a idéia de origem. É o que nos sugere a seguinte passagem, na qual Freud recusa a eleição de um único fator que pudesse responder pela formação de um sintoma: "Buscar a etiologia das neuroses exclusivamente na hereditariedade ou na constituição seria tão unilateral quanto atribuir essa etiologia às influências acidentais que atuam sobre a sexualidade no decurso da vida do paciente" (Freud, [1906 [1905]] 1974: 291292). Voltemo-nos, portanto, mais detidamente, para as transformaçóes na teoria freudiana.

\section{DA SEDUÇÃO À FANTASIA}

Uma das primeiras tentativas de estabelecer a possível origem do sintoma foi efetuada a partir da noção de trauma (Freud, [1950 [1895]] 1974). Extraído do discurso médico, este termo remete-nos à idéia de lesão física decorrente de um choque intenso. No campo que começa a se constituir, a noção se apóia nesta concepção, mas vai ganhar um outro estatuto. Se o caráter de lesão física não dava conta de explicar o sintoma, a ação de um choque violento vinculado a um esquecimento podia ser compreendida a partir de um novo referencial. $\mathrm{O}$ embate entre 
explicação e compreensão, ou seja, entre a ordem da razão e a ordem do sentido, está aí colocado. Tratava-se, segundo a perspectiva psicanalítica, de uma experiência traumática vivida passivamente em tenra infância e de caráter sexual. Uma cena de sedução, presente no relato das pacientes, e que Freud remetia à ação perpetrada por um adulto - em geral o pai das mesmas -, se configurava como ponto de partida para a causação de uma neurose.

Já podemos entrever uma diferença em relação ao discurso médico em voga: o trauma não é visto na lesão anatômica, mas escutado na comunicação que é feita pelas histéricas. A experiência traumática vivida na infância ganha foro de verdade sem ter sido verificada, ou melhor, é como trauma psíquico que a primeira experiência pode ser considerada. É importante salientar que, por mais que Freud tenha procurado se identificar com o pensamento científico no que diz respeito ao embate entre explicação e compreensão - expressão da querela dos métodos das ciências naturais contra as ciências humanas -, a psicanálise fica, com efeito, à margem da questão. Afinal, como veremos adiante, se num primeiro momento Freud opta pela ordem do sentido, e mais tarde pelo registro da compreensão que esta ordem implica, perde o vigor no método psicanalítico o anseio pela causalidade dos sintomas. Desde o início de suas investigações sua diferença com respeito ao discurso médico vigente - da ordem das causas - indica que Freud não valoriza o fato, mas a idéia: não era o braço anatomicamente construído, mas a representação de braço, não era a lesão, mas o choque violento, o efeito da colisão.

Em 1897, Freud começa uma carta dirigida a Fliess da seguinte maneira: "Não acredito mais em minha neurótica" (Freud, [1897] 1974: 350). Referia-se à sua teoria a respeito das neuroses, sobretudo à etiologia traumática a partir de uma experiência sexual vivida passivamente. Ele expõe claramente os motivos que o levaram a isso: em primeiro lugar a ausência de êxitos em realizar uma análise completa e o abandono do tratamento por parte dos pacientes em casos que pareciam estar sendo elucidados satisfatoriamente. Além disso, percebeu que todos os pais eram tidos como perversos, levando a crer que este quadro seria inclusive mais freqüente do que a histeria. Em terceiro lugar, expõe o entendimento de que "no inconsciente não há indicação de realidade" (Freud, [1897] 1974: 351). Finalmente, a impossibilidade de trazer por completo à consciência as experiências infantis. Ele chega a evidenciar na referida carta que a resistência do consciente jamais seria superada pelo conteúdo inconsciente. Assim sendo, as histéricas não teriam como lembrar da suposta cena de sedução.

Entretanto, esta cena estava presente em suas queixas. Elas relatavam terem sido objeto de uma sedução, embora isto não tivesse acontecido factualmente. A verdadeira reviravolta expressa na tese freudiana é a recusa a negligenciar a sedu- 
ção apenas por esta não ter se dado "materialmente". Embora não tivesse ocorrido, não deixava de produzir efeitos. Não cabia mais desconsiderar a fala das histéricas; era a ordem da ficção que passava a ter relevância: "Se os pacientes histéricos remontam seus sintomas a traumas que são fictícios, então o fato que surge é precisamente que eles criam tais cenas na fantasia, e essa realidade psíquica precisa ser levada em conta ao lado da realidade prática” (Freud, [1914a] 1974: 27-28).

$\mathrm{O}$ autor observou que as fantasias tinham a importante função de encobrir a atividade auto-erótica da mais remota infância, trazendo à tona a existência de uma atividade sexual também nos pequeninos (Freud, [1905] 1974). A sexualidade infantil era o elemento que faltava para melhor fundamentar o abandono da teoria da sedução. A fantasia de ter sido seduzido encobria a atividade sexual infantil, inconcebível para os preceitos morais da época. Freud constatara que o método interpretativo era ineficaz frente à revelação de uma sedução real e traumática, vivida passivamente nos primeiros anos da infância. Isso porque, se antes achava que poderia recuperar integralmente todas as neuroses, curando-as, agora colecionava impasses indicativos de que a interpretação não poderia produzir a rememoração por completo. A experiência de sedução como a grande origem dos sintomas histéricos dá lugar então à fantasia; mais precisamente, as fantasias inconscientes são as responsáveis por organizar o psiquismo. Ao afirmar que não acreditava mais em sua antiga teoria das neuroses, abria mão da sedução factual para dar lugar àquela fantasiada, supondo, com isso, não tanto uma origem, mas a idéia de começo organizado pela fantasia.

A noção de começo, como vamos ressaltar adiante, coloca em pauta a multiplicidade de impressóes psíquicas, donde o psiquismo seria organizado e, em última instância, também o sintoma. Trata-se de uma perspectiva diferente daquela que elege a cena de sedução como o ponto de origem, a partir do qual tudo seria determinado. Esta concepção revela a subversão freudiana com relação ao discurso médico. Ademais, gradativamente, também a suspeita de que todo o conteúdo psíquico poderia ser interpretado vai perdendo o vigor, culminando com o conceito de pulsão de morte (Freud, [1920] 1974). Vamos acompanhar esta passagem no tópico que se segue.

\section{A VIRADA DE 1920}

No ano de 1920, Freud colecionava impasses teóricos e clínicos, em especial no que concernia à sua perspectiva sobre o sintoma e o método que lhe era correspondente. Os pacientes expressavam forte resistência ao tratamento, embora não se mostrassem cônscios disso. Já não era mais possível desviar a atenção das resis- 
tências ao trabalho de análise, que irrefutavelmente colocavam em questão também os alicerces teóricos freudianos. Posteriormente, a reação terapêutica negativa ganharia destaque nos estudos freudianos sobre o supereu (Freud, [1923] 1974), mas já neste momento Freud evidenciava como o progresso do tratamento era perturbado por uma força que se revelava mais forte que a própria vontade de se ver livre da doença.

É diante deste cenário que Freud chega à postulação da pulsão de morte. Se, por um lado, desde a consideração de que também o ego é investido libidinalmente, a oposição entre pulsões do ego e pulsões sexuais sofria abalos (Freud, [1914b] 1974), também a constatação de tais fenômenos clínicos exigia novas formulações a respeito da teoria das pulsões. É, portanto, em torno dos desdobramentos de seu estudo sobre o narcisismo e da postulação da compulsão à repetição (Freud, [1919] 1974) que a teoria freudiana passará por importantes transformações.

A pulsão de morte aparece, no contexto de 1920, referida a uma dimensão intensiva, algo que escapa ao sistema de representações. Trata-se, entretanto, da radicalização de uma perspectiva que já se fazia presente em "As pulsões e suas vicissitudes" ([1915] 1974). Isso porque neste trabalho o registro das intensidades é tomado como pregnante. A pulsão como "medida da exigência feita à mente no sentido de trabalhar em conseqüência de sua ligação com o corpo" (Freud, [1915] 1974: 142), como força constante contra a qual qualquer tentativa de fuga parece ineficaz, expõe o caráter intensivo da definição freudiana. Caráter que vai concorrer para a idéia de um indeterminismo psíquico. Sem dúvida, o próprio âmbito representacional já indicava certa dominação da força pulsional. Acompanhando Birman (1997), podemos dizer que a pulsão é, portanto, uma força "que precisa ser submetida a um trabalho de ligação e de simbolização para que possa se inscrever no psiquismo propriamente dito. Esse processo foi denominado domínio da força pulsional, que se realizaria simultaneamente nos registros do objeto e da representação, de forma a se constituir o circuito pulsional” (Birman, 1997: 63). Ou seja, a noção de representação parece conceder parte de sua importância para a dimensão intensiva, o que vai se acentuando cada vez mais nos postulados freudianos.

No texto "O estranho" ([1919] 1974), Freud nomeia a compulsão à repetição como o que coloca em xeque o princípio de prazer/desprazer, de caráter demoníaco, responsável por uma repetição estranha ao sujeito. Não se pode mais explicar certas situações à luz da hipótese de que, quando há prazer para um sistema, noutro se encontra desprazer. Do mesmo modo, não cabe mais procurar exclusivamente um significado oculto nas formações do inconsciente, método exposto em "A interpretação dos sonhos" ([1900] 1974). Aliás, mesmo no referi- 
do texto Freud já menciona um núcleo não analisável, o umbigo dos sonhos, que permanece enigmático na ocasião, mas não deixa de se fazer presente como o que vem de encontro ao método interpretativo. Com efeito, a compulsão à repetição revela um choque da repetição com o sentido. A insistência da repetição coloca o sujeito frente à sua indeterminação. Se a noção de representação da pulsão poderia assegurar um vestígio determinista, este se perde inteiramente com a pulsão de morte. Não é possível eleger um ponto de determinação, que o sujeito conhecerá a partir do tratamento analítico. Ao contrário, a experiência de uma análise confronta o sujeito com sua indeterminação fundamental, levando-o justamente ao limite da determinação, a um lugar vazio de significações. Este ponto de chegada evidencia o fracasso do ideal iluminista de cura em psicanálise, o qual sustentava o imperativo da remissão sintomática, encarcerando o sintoma em uma perspectiva negativista.

Se anteriormente Freud elevava a promessa de cura ao lugar de bússola de suas hipóteses, em especial após a postulação da pulsão de morte, este princípio norteador perde em definitivo sua remota importância. $\mathrm{O}$ pensamento freudiano torna cada vez mais explícitos os impasses frente ao projeto de estabelecer uma terapêutica calcada na retórica determinista da ciência moderna. Mas, se não é prometido ao sujeito que procura uma análise a cura de suas neuroses, o que se faz então? É evidente que não se trata de dizer que a psicanálise não produza efeitos na existência dos sujeitos, "mas sim enunciar que essas transformações e inflexões não são da ordem da cura e da terapêutica” (Birman, 1997: 44), porém, mais propriamente, da ordem de um modo de existência. Se os sintomas são atrelados a um estilo de existência, perde o vigor a tentativa de associar a eliminação daqueles a uma promessa de cura.

Passaremos em seguida a esta temática, mas não sem antes contextualizar historicamente esta inflexão que se observou no seio das formulações freudianas. Vimos como não cabe, pois, falar de origem. A pulsão de morte conduz esta idéia às últimas conseqüências, na medida em que não é representável, sendo justamente o que escapa ao sistema de representações. Se anteriormente era possível detectar na elaboração de Freud uma teoria a respeito da origem (Freud, [1983-85] 1974), vimos como logo se destacou desta perspectiva ao privilegiar uma pesquisa do começo, que conta com múltiplos elementos reunidos ao acaso e não um único a ser eleito como causa determinante ${ }^{2}$. Diversamente da origem do sintoma, o começo deste se delineia a partir de inúmeros fatores condicionantes e concorrentes. Mas entendemos que o declínio da idéia de origem não foi exclusivo do pensamento freudiano, pois começou a se configurar como uma característica da própria Modernidade. 


\section{HISTORICIZAR É PRECISO!}

A noção de processo histórico aparece como uma produção do século XIX. Ele se destina a descrever como algo se desdobra ao longo de uma história, organizando, portanto, um discurso. Trata-se, pois, de uma característica da Modernidade (Foucault, [1966] 2002). Diferindo desta perspectiva, na Idade Clássica predominava a noção de representação. Ora, o fundamental era dedicar-se à representação do pensamento e de que maneira esta se dava. Neste contexto, é viável pensar a busca por uma origem absoluta, tarefa à qual se dedicavam as disciplinas científicas, uma vez que as idéias representam as coisas, isto é, o significante remete necessariamente a um significado, sendo que sujeito e objeto têm como liga a representação.

Esta concepção, denominada de pensamento da Identidade ou da representação, foi ferozmente criticada por autores que propõem em seu lugar o pensamento da Diferença. Foucault desponta como um de seus principais representantes, como sugere o seguinte trecho: "A repetição que tinha sido pura exterioridade, pura figura de origem, converte-se agora em debilidade interna, defeito da finitude, espécie de tartamúdio do negativo: neurose da dialética. Assim, a filosofia da representação conduz à dialética" (Foucault, 1980: 62). Uma das críticas recaía sobre a tentativa caduca de descartar a diferença, buscando sem cessar uma identidade entre sujeito e objeto. Para estes teóricos, a diferença não poderia estar submetida à identidade, cujo fundamento seria transcendente, seja numa determinada ordem de realidade ou como modo de conhecimento (Herzog, 1999). Críticas como estas também foram lançadas à psicanálise, acusada de estar inserida em um pensamento de transcendência - sobretudo devido à postulação da universalidade do complexo de Édipo -, assim como pela leitura que a coloca na esteira da filosofia da representação. Entretanto, "apesar da pertinência da idéia de um Freud tributário do pensamento da representação, também é possível designá-lo como precursor de uma nova racionalidade, que tem sustentação teórica no pensamento da Diferença" (Herzog, 1999: 61). O mais importante para o presente trabalho é destacar como a psicanálise se descola da idéia de se chegar a um princípio, ou a uma finalidade última, ambas perspectivas calcadas no pressuposto de um fundamento.

A garantia de uma origem está, de saída, excluída. Foucault (1980) fala de dialética para mostrar como se entra em uma circularidade do discurso, de modo a não ser possível chegar a um ponto último a partir do qual tudo seria determinado. Para darmos corpo a esta mudança moderna, basta pensarmos nas teses acerca das raízes da civilização. Os modernos exaltavam a tese da constituição violenta da 
humanidade, evidenciando a idéia de futuro e não mais de retorno a um passado perdido, o qual poderia ser resgatado: "A história como evolução de uma bestialidade primitiva contrapõe-se diretamente ao mito da perfeição que está na Origem, a uma originária bondade e unidade dos homens" (Farah, Herzog \& Mograbi, 2006: 50).

Neste sentido, podemos afirmar que o pensamento freudiano tornou-se moderno apenas a partir do abandono da teoria da sedução. A máxima "não acredito mais em minha neurótica" pode ser convertida em "não acredito mais em uma origem". Esta mudança não se deu sem importantes conseqüências. Consideramos que a principal destas diz respeito à restrição de uma perspectiva determinista. Se antes era possível conceber uma teoria normativa, que almejava a cura e o progresso - o que concedeu espaço a inúmeras críticas (Farah \& Herzog, 2005) -, agora não era mais viável sustentar um projeto de assepsia das neuroses.

Nas formulações modernas, a idéia de origem não se sustenta, cedendo espaço para os processos de historicização. Foucault ([1969] 2005) critica a noção de fundamento ou de condiçôes de possibilidade para que algo se dê, para que um sintoma se constitua, por exemplo. Ele propóe pensarmos em termos de estratégias discursivas, as quais formariam princípios organizadores. $\mathrm{O}$ que produz descontinuidades são os confrontos entre os referidos sistemas de estratégias. Há, portanto, um embate no nível dos enunciados. O próprio sujeito é tido como um ponto de chegada, a partir desses embates, e não como uma origem em si.

Esta visada que ganha força na Modernidade tem seu lugar também no pensamento freudiano. $\mathrm{O}$ sujeito não é tomado enquanto origem, mas como um destino da pulsão. Da mesma maneira compreendemos o conceito de sintoma como um ponto de chegada e não de partida, perdendo ênfase a tarefa de nos ocuparmos da pesquisa de sua origem. Mas o que fazer frente ao padecimento daqueles que de seus sintomas se queixam em nossa prática clínica? Que estatuto conferir ao sintoma hoje? Apesar dos anos que nos afastam da Idade Clássica, atualmente muitas são as promessas de se chegar a uma (improvável) origem última do sofrimento, a partir do que tudo poderia ser diagnosticado e seguramente remediado. Em contrapartida, a psicanálise faz jus aos postulados freudianos, apontando a dimensão irremediável do conflito, o desajuste inerente às relações humanas e à insensatez da promessa de cura absoluta para os sintomas. Entretanto, paralisar diante de tantas impossibilidades não nos parece uma saída psicanalítica, principalmente se revisitarmos os primeiros estudos de seu fundador, que não recuou frente às dificuldades e nem se mostrou resignado com estas constatações. Mas também não se lançou em uma aventura que objetivasse garimpar soluções fantásticas para os males da humanidade, prometendo a cura e a felicidade irrestrita. 
Passaremos a discutir o campo de pensamento que se abre a partir desta mudança de perspectiva acerca da origem. Esta discussão deve viabilizar, também, novas perspectivas para tratarmos a própria questão do sintoma.

\section{A SINGULARIDADE DO SINTOMA}

Vimos como Freud se distinguiu dos postulados da ciência moderna. Esta calcava seu discurso no registro das enfermidades, ao passo que a psicanálise prometia um novo lugar para o sintoma, desde seus trabalhos mais iniciais: "a noção de neurose foi deslocada do contexto da problemática da enfermidade, para ser colocada como uma das possibilidades de ordenação de um 'aparelho psíquico' submetido a conflitos mentais" (Birman, 1989: 53). O sintoma neurótico evidencia o conflito irremediável entre o desejo e a censura que lhe é correspondente. No entanto, possui também um caráter de conciliação entre as duas forças opostas: o desejo é satisfeito, tendo em vista que o sintoma é substituto de uma satisfação impossível de ser alcançada, e a censura também se faz presente, na medida em que o conteúdo inconsciente se revela de maneira distorcida, condizente com os preceitos morais. Freud ([1908] 1974) pontuara como a neurose representa uma satisfação substitutiva frente à exigência de renúncia pulsional por parte da moral sexual civilizada. Pode-se depreender, portanto, que também cabe ao sintoma neurótico certa ordenação psíquica.

Esta perspectiva marca uma subversão em relação aos postulados científicos da época, balizados pelos ideais de cura e progresso. A histeria não só parecia molestar os que dela se queixavam como os afastava da realidade, danificando seu potencial de sociabilidade. Como compatibilizar uma sociedade supostamente frutífera e aspirante ao progresso com sujeitos histéricos? Este mal deveria ser extirpado através do método advindo da investigação científica. Freud, ao contrário da medicina que tomava como referência o corpo doente, ocupou-se do sujeito e entendeu que o desejo de cura não poderia nortear o processo psicanalítico. Conforme verificamos, enquanto a ciência se ocupava da ordem da causalidade orgânica, Freud apostava na ordem do sentido. Não havia uma causalidade expressa no corpo que pudesse abarcar os fenômenos histéricos, mas sim um sentido inerente ao sintoma que muito poderia dizer a respeito da história do sujeito e da função de sua doença para a ordenação de seu psiquismo: "é a ordem do sentido que funda o campo de positividade da clínica psicanalítica" (Birman, 1989: 161).

Nesses termos, não é mais pertinente investigar a origem do sintoma; mais do que uma origem, o sintoma tem uma originalidade. Assoun (1984), ao discutir os conceitos que apontariam para um início em Freud, propõe utilizarmos a no- 
ção de arcaico em vez de nos ocuparmos de uma origem propriamente dita. Esta remonta a um objeto preexistente, a algo que está dado e basta ser encontrado, ao passo que aquela se apresenta como traço de um percurso. $\mathrm{O}$ arcaico é tomado como um predicado que aponta para uma função de origem e não como uma verdade subjacente que poderia ser buscada para se chegar ao ponto último do sintoma. Estamos, pois, no campo de um constante devir, de um processo dinâmico que não comporta a idéia de uma causa que forneceria a chave para a compreensão dos mistérios do sintoma. O sentido deste, mais do que sua origem última, este sim nos parece importante na concepção psicanalítica.

O processo analítico visa a abertura do sujeito ao sentido, valorizando os enigmas que os analisandos diversas vezes esperam dissipar lançando questões ao analista. Diferente de uma visada que pretende alcançar a unidade do ego, concorrendo para o bem-estar subjetivo, a psicanálise espera restituir a singularidade sem estacionar no registro das enfermidades. Por este mesmo motivo a noção de sujeito nos é tão cara! Não nos cabe prometer uma cura milagrosa, mas convidar os analisandos a um trabalho que coloca a "individualidade diante de um movimento que se realiza no sentido contrário de sua posição habitual, isto é, de se situar apenas no plano do ego unificante, que seria sancionado pelos processos de normalização da individualidade" (Birman, 1989: 149).

Ao contrário de uma concepção normativa da individualidade, espera-se positivar o que há de mais singular em cada discurso, em cada subjetividade. Também ao sintoma cabe a manifestação de uma originalidade, que extravasa as categorias diagnósticas e mesmo todo o conhecimento prévio que um analista poderia supor possuir. Dessa maneira, não nos apraz silenciá-lo, extirpando-o como um corpo estranho que invade o psiquismo, mas dar-lhe voz para que o que há de mais particular no sujeito se manifeste. Ainda hoje a psicanálise se vê diante de pesadas críticas (Mograbi \& Herzog, 2006) que vão ao encontro da exaltação midiática de um imperativo de saúde irrestrita, evidenciada em promessas de saídas milagrosas e instantâneas para todo e qualquer tipo de mal. Com efeito, estes intentos não devem fazer parte de um processo psicanalítico, um dos motivos que levam a supor que a psicanálise esteja em crise na atualidade, seja por se revelar ineficaz frente a este projeto, seja por se supor que os postulados freudianos devem ser modificados para uma investigação de novas manifestações sintomáticas ${ }^{3}$. Frente a estes apontamentos, apostamos na retomada das considerações de Freud para lançar luz à temática dos sintomas e da técnica psicanalítica.

Se Freud abandonou a pesquisa da origem, ocupando-se da multiplicidade de impressões que concorrem para a formação do sintoma, também não elegemos um único ponto que responda por este, mas extrapolamos a pesquisa de suas 
causas para o tomarmos como fonte de onde emana a originalidade do sujeito. A busca da origem do sintoma acabava concorrendo para silenciar o sujeito, o que foi marcadamente característico da ciência moderna, que se preocupava com relaçôes causais e lesôes visíveis para o olhar científico, sem se preocupar com a escuta do sofrimento dos pacientes e, em última instância, excluindo o sujeito. Se em vez da origem do sintoma pensarmos no sintoma como origem, passamos à sua dimensão inventiva, ao que se revela como original no sujeito, descortinando muitos de seus mistérios. Configura-se como igualmente importante ainda a sustentação de que o sintoma possui uma função, que ordena a vida anímica e acaba contribuindo para estruturar também as relações humanas. Afinal de contas, também não nos colocamos e nos relacionamos através de nossos sintomas?

\section{REFERÊNCIAS BIBLIOGRÁFICAS}

Assoun, P. L. (1981). Introdução à epistemologia freudiana. Rio de Janeiro: Imago. . (1984). L'entendement freudien: Logos et Anankè. Paris: Gallimard.

Bauman, Z. (1998). O mal-estar na pós-modernidade. Rio de Janeiro: Jorge Zahar.

Bernardes, M. C. N. (2000). O sujeito entre sobredeterminação e escolha. Dissertação de Mestrado. Curso de Pós-Graduação em Teoria Psicanalítica, Universidade Federal do Rio de Janeiro.

Birman, J. (1989). Freud e a experiência psicanalitica. Rio de Janeiro: Taurus-Timbre. . (1997). Sujeito e estilo em psicanálise: sobre o indeterminismo da pulsão no discurso freudiano. Em Estilo e modernidade em psicanálise (pp. 43-69). São Paulo: Editora 34.

- (2000). Mal-estar na atualidade: a psicanálise e as novas formas de subjetivação. Rio de Janeiro: Civilização Brasileira.

Chaves, E. (1988). Foucault e a psicanálise. Rio de Janeiro: Forense Universitária.

Farah, B. \& Herzog, R. (2005). A psicanálise e o futuro da civilização moderna. Psyché, ano IX, 16, 49-64.

Farah, B.; Herzog, R. \& Mograbi, D. (2006). Da superação à simultaneidade: crise e política na psicanálise. Em Bastos, A. (Org.). Psicanalisar hoje (pp. 37-65). Rio de Janeiro: Contra Capa.

Foucault, M. (1966). As palavras e as coisas: uma arqueologia das ciências humanas. São Paulo: Martins Fontes, 2002.

. (1969). A arqueologia do saber. Rio de Janeiro: Forense Universitária, 2005. . (1980). Nietzsche, Freud e Marx. Porto: Publicações Anagrama. 
Freud, S. (1893-95). A etiologia da histeria. Obras completas, ESB, v. II. Rio de Janeiro: Imago, 1974.

- (1895). Extratos dos documentos dirigidos a Fliess - Rascunho K. Obras completas, ESB, v. I. Rio de Janeiro: Imago, 1974.

- (1897). Extratos dos documentos dirigidos a Fliess - Carta 69. Obras completas, ESB, v. I. Rio de Janeiro: Imago, 1974.

- (1899). Extratos dos documentos dirigidos a Fliess - Carta 125. Obras completas, ESB, v. I. Rio de Janeiro: Imago, 1974.

- (1900). A interpretação dos sonhos. Obras completas, ESB, v. V. Rio de Janeiro: Imago, 1974.

- (1905). Três ensaios sobre a teoria da sexualidade. Obras completas, ESB, v. VII. Rio de Janeiro: Imago, 1974.

- (1906 [1905]). Meus pontos de vista sobre o papel desempenhado pela sexualidade na etiologia das neuroses. Obras completas, ESB, v. VII. Rio de Janeiro: Imago, 1974.

- (1908). Moral sexual "civilizada" e doença nervosa moderna. Obras completas, $E S B$, v. IX. Rio de Janeiro: Imago, 1974.

- (1914a). A história do movimento psicanalítico. Obras completas, ESB, v. XIV. Rio de Janeiro: Imago, 1974.

- (1914b). Sobre o narcisismo: uma introdução. Obras completas, ESB, v. XIV. Rio de Janeiro: Imago, 1974.

- (1915). As pulsões e suas vicissitudes. Obras completas, ESB, v. XIV. Rio de Janeiro: Imago, 1974.

- (1919). O estranho. Obras completas, ESB, v. XVII. Rio de Janeiro: Imago, 1974.

- (1920). Além do princípio do prazer. Obras completas, ESB, v. XVIII. Rio de Janeiro: Imago, 1974.

- (1923). O eu e o isso. Obras completas, ESB, v. XIX. Rio de Janeiro: Imago, 1974.

- (1950 [1985]). Projeto para uma psicologia científica. Obras completas, ESB, v. I. Rio de Janeiro: Imago, 1974.

Herzog, R. (1999). Da falta à ausência de referência: o vazio na psicanálise. Ágora, v. II (1), 55-73.

Kristeva, J. (2002). As novas doenças da alma. Rio de Janeiro: Rocco.

Melman, C. (2003). O homem sem gravidade. Rio de Janeiro: Companhia de Freud.

Mograbi, D. \& Herzog, R. (2006). Sob o signo da incerteza: autoridade simbólica e desamparo. Estudos de Psicologia, 11 (2), 127-133. 


\section{NOTAS}

1 A idéia de escolha da neurose aparece algumas vezes nos textos freudianos. O agente que a determinaria não é o mesmo em todos os momentos, mas a noção de escolha perdura por todo seu pensamento. A expressão revela que o sujeito está inteiramente implicado no desenvolvimento de certo tipo de neurose.

2 Para uma investigação mais aprofundada remetemos o leitor aos textos Nietzsche, Freud e Marx (Foucault, 1980) e Foucault e a psicanálise (Chaves, 1988).

3 Dentre os autores de referência que já se dedicaram à discussão da psicanálise na contemporaneidade indicamos, entre outros, Bauman (1998), Kristeva (2002) e Melman (2003).

Recebido em 15 de maio de 2007 Aceito para publicação em 13 de agosto de 2007 